\title{
ANÁLISE DE MANIFESTAÇÕES PATOLÓGICAS EM ESTRUTURAS DE CONCRETO ARMADO EM AMBIENTE AGRESSIVO: ESTUDO DE CASO
}

\author{
LAGARES, BÁRBARA FERNANDES PORTO \\ Profissão: Engenheira Civil \\ Instituição: Centro Universitário Uninovafapi \\ Estado: Piauí; País: Brasil \\ e-mail: eng.barbaraporto@gmail.com
}

\author{
FERREIRA, CAROL CHAVES MESQUITA E \\ Profissão: Engenheira Civil \\ Instituição: Centro Universitário Uninovafapi \\ Estado: Piauí; País: Brasil \\ e-mail: carol_arqeng@yahoo.com.br
}

\author{
FERNANDES, JOSÉ FELIPE G. MEDEIROS \\ Profissão: Engenheiro Civil \\ Instituição: Centro Universitário Uninovafapi \\ Estado: Piauí; País: Brasil \\ e-mail: jffernandes000@gmail.com
}

\author{
BITENCOURTE, FRANCISCO CARLOS LOPES \\ Profissão: Engenheiro Civil \\ Instituição: Centro Universitário Uninovafapi; UFG \\ Estado: Piauí; País: Brasil \\ e-mail: carlosbitencourte@gmail.com
}

\author{
VELOSO, THAIS SILVA \\ Profissão: Engenheira Civil \\ Instituição: Unyleya; FAESF \\ Estado: Piauí; País: Brasil \\ e-mail: thaisveloso.eng@gmail.com
}

\section{RESUMO}

Este trabalho tem como objetivo identificar as manifestações patológicas mais recorrentes em uma estrutura de concreto armado localizada próxima ao mar no estado do Piauí. Este estudo de caso é de caráter qualitativo em um auditório inativo. Possui também natureza descritiva e exploratória. Analisou-se a alcalinidade e a presença de íons cloreto nos pilares e vigas. Os resultados de laboratório para quantificação de cloretos em alguns dos pilares foram feitos na Universidade Federal do Piauí com o auxílio de um profissional da área. Nos pilares estudados em campo, as armaduras estavam expostas, os cobrimentos dos pilares estavam destacados, o aço da estrutura inteira estava corroído devido à quebra da camada passivadora, as bases dos pilares estavam degradadas, as vigas da fachada oeste estavam em um estado tolerável, porém as da fachada leste estavam em estado crítico. Nos corpos de prova retirados de alguns pilares, a presença dos íons cloreto ultrapassava o permitido por norma. A estrutura sofre por uma falta de manutenção periódica, por conta do descuido causado pela sua inatividade, que acarretou na redução da sua vida útil. A presença de íons cloreto nos pilares agregada a um pequeno cobrimento executado nos pilares confirma a penetração da maresia no concreto que avançou até a armadura. A tensão causada no aço permite a manifestação de trincas e fissuras na superfície facilitando ainda mais a entrada de agentes externos. Dessa forma, a entrada do gás carbônico por essas aberturas possibilitou a redução da alcalinidade do concreto ocasionando a quebra da camada passivadora do aço e posteriormente no avanço incontrolável da corrosão.

Palavras-chave: Manifestações Patológicas, Maresia, Corrosão, Manutenção.

\section{ABSTRACT}

This paper aims to identify the most recurrent pathological manifestations in a reinforced concrete structure located near the sea in the state of Piauí. This case study is qualitative in an inactive auditorium. It also has a descriptive and exploratory nature. The alkalinity and the presence of chloride ions in the columns and beams were analyzed. Laboratory results for chloride quantification in some of the pillars were made at the Federal University of Piauí with the help of a professional in the area. In the field studied pillars, the reinforcement was exposed, the pillar coverings were detached, the steel of the entire structure was eroded due to the break of the passivating layer, the pillar bases were degraded, the west facade beams were in a tolerable state, but those on the east facade were in critical condition. In specimens removed from some pillars, the presence of chloride ions exceeded what is normally allowed. The structure suffers from a lack of periodic maintenance, due to the carelessness caused by its inactivity, which resulted in the reduction of its useful life. The presence of chloride ions in the columns added to a small covering made in the columns confirms the penetration of the salt spray into the concrete that has advanced to the reinforcement. The tension caused in the steel allows cracks and cracks to appear on the surface making it even easier for external agents to enter. Thus, the 
entry of carbon dioxide through these openings made it possible to reduce the alkalinity of the concrete causing the breakdown of the passivating layer of steel and subsequently the uncontrollable advance of corrosion.

Keywords: Pathological manifestations, Maresia, Corrosion, Maintenance.

\section{INTRODUÇÃO}

Segundo Helene (1992), a vida útil de uma obra está diretamente ligada ao bom andamento das etapas necessárias para toda construção: planejamento, projeto, fabricação de materiais e componentes fora do canteiro, execução propriamente dita e o uso, que envolve a operação de manutenção tanto preventiva como corretiva.

Conforme a norma brasileira 6118 (ABNT, 2014), o concreto presente nas estruturas deve atender a três aspectos: capacidade resistente, durabilidade e desempenho em serviço. Existem condições mínimas de execução que visam a boa qualidade do concreto como, também, a proteção de sua armadura contra agentes físicos, biológicos e químicos. Estas técnicas construtivas evitam patologias decorrentes das características do local onde está sendo construído (BRANDÃO, 1998).

Para evitar a ação de agentes externos que prejudicam a estrutura de concreto armado, assim como em qualquer outro tipo de estrutura, existem algumas determinações quanto à espessura do concreto - que servirá como capa de proteção física à armadura, conforme a NBR 6118. Elas são estabelecidas em classes de agressividade de I a IV, conforme o nível da agressão. Em regiões litorâneas, esta classe é definida no nível III, quando a estrutura não recebe respingos da maré, o que acarreta um cobrimento de 40 milímetros. Porém, quando ocorre a presença dos respingos, a classe de agressividade torna-se de nível IV, recebendo um cobrimento de 50 milímetros, conforme estabelece a NBR 6118 (ABNT, 2014).

Os ambientes agressivos tendem a ter um alto teor de sais nas camadas de solos presentes na região que acarretam falhas, principalmente, em fundações. A baixa consistência das areias litorâneas impossibilita uma estabilidade das edificações, e, desse modo, o aparecimento de trincas e fissuras decorrentes do recalque das fundações são bem evidentes (MILITITSKY, CONSOLI E SCHANID, 2008).

Portanto, pensou-se em explorar as manifestações patológicas recorrentes nas estruturas de concreto armado em uma edificação litorânea do Piauí. Com isso, chega-se à seguinte problematização: Quais as manifestações patológicas mais abrangentes em ambientes agressivos com as características do estudo de caso? Qual a importância de um cobrimento | dimensionado corretamente e bem executado em ambientes onde o ataque marítimo é significativo?

\section{REFERENCIAL TEÓRICO}

\subsection{Concreto e Armadura}

Segundo material mais consumido do mundo, perdendo apenas para a água, o concreto é um material formado por cimento, agregados (graúdos e miúdos), água e, em algumas situações, aditivos. O concreto possui propriedades mecânicas capazes de resistir à compressão, mas não tanto em relação à tração, por isso a necessidade de um elemento que resista a este tipo de esforço: a armadura. As estruturas de concreto devem ser plenas em sua utilização para a qual foi projetada, não oferecendo riscos de ruptura, sem danos que comprometa a estrutura e capazes de resistir aos fatores | ambientais, nesse caso, a agressividade do ambiente litorâneo (ABNT, 2014).

O ambiente litorâneo possui dois mecanismos preponderantes de deterioração da armadura: por ação do gás carbônico ao penetrar no concreto e alcançar a armadura, desencadeando a despassivação por carbonatação; e pelo elevado teor de íons cloreto no ar (ABNT, 2014). É muito comum apresentar corrosão na armadura, causando muitos prejuízos e tendo uma recuperação dispendiosa e de execução complicada. Conhecer a causa de patologias que atinjam a armadura pode evitar sua manifestação. A corrosão da armadura ocorre por um efeito pilha, de forma que o aço é substituído por | ferrugem, tornando-o fraco em relação a sua resistência mecânica (MENDES, 2018).

\section{2 $\mathrm{O}$ concreto armado em ambiente agressivo}

As ondas marinhas retiram sais do mar que são transportados pelo ar. Elas conseguem percorrer longas distâncias e se depositam sobre o concreto na forma de gotas de água. Os íons cloretos são muito pequenos e possuem grande mobilidade dentro do concreto. O princípio é evitar ou diminuir a contaminação da estrutura: através da posição e localização da obra em relação a orla e/ou uso de materiais mais resistentes a agressividade do ambiente, como concretos mais impermeáveis, concretos com baixa relação água-cimento, aditivos que reduzem a porosidade do 
concreto, inibidores químicos que protegem a armadura da corrosão, revestimentos impermeáveis, protetores contra penetração de cloreto na superfície do concreto (HELENE, 1986).

\subsection{Patologias no concreto armado}

Origens e causas de defeitos nas construções civis são estudadas pelas patologias nas estruturas de concreto. Os problemas patológicos têm manifestações características e através delas, pode-se prever a procedência e as consequências de sua manifestação. Os sintomas mais comuns de acontecerem em estruturas de concreto são as fissuras, as eflorescências, as flechas excessivas, as manchas aparentes no concreto, os ninhos de concretagem e a corrosão das armaduras, sendo esta última mais incidente em edificações litorâneas devido à maré (HELENE, 1992).

O processo construtivo tem cinco etapas: planejamento, projeto, fabricação de materiais, execução e uso. As quatro primeiras duram 2 anos ou menos, enquanto o uso dura 50 ou mais anos. A maioria dos problemas patológicos se manifestam na fase de execução e uso. Diagnosticar adequadamente pode indicar em que etapa do processo construtivo originou a patologia (HELENE, 1992).

\subsubsection{Carbonatação}

Segundo Gentil (2007), a carbonatação ocorre devido à redução do pH em uma estrutura e pode ser possibilitado pela penetração do gás carbônico $\left(\mathrm{CO}_{2}\right)$ no concreto através dos poros na superfície, que reage com o hidróxido de cálcio, $\mathrm{Ca}(\mathrm{OH})_{2}$, presente na composição do cimento, gerando carbonato de cálcio, conforme a reação (1) abaixo:

$$
\mathrm{CO}_{2}+\mathrm{Ca}(\mathrm{OH})_{2} \rightarrow \mathrm{CaCO}_{3}+\mathrm{H}_{2} \mathrm{O}
$$

Gentil (2011) relata que o carbonato de cálcio, $\mathrm{CaCO}_{3}$, tem um $\mathrm{pH}$ menor que 7, caracterizando uma substância ácida e, ao entrar em contato com o concreto, que tem pH básico (entre 12,5 e 13,5), ocorre um processo de quebra da camada passivadora do aço. Este processo de redução de alcalinidade é chamado de carbonatação que desencadeia uma série de manifestações nas estruturas. Uma delas é a quebra da camada passivadora do aço e, quando ocorre, permite a sua exposição ao ambiente de forma generalizada.

Para Gentil (2007), o processo de carbonatação pode, também, ocorrer através da reação do gás carbônico $\left(\mathrm{CO}_{2}\right)$ com a água presente ou no concreto (presente no processo de molhagem da argamassa) ou provinda do ambiente, aparente na superfície do concreto. Esta reação resulta na produção do ácido carbônico $\left(\mathrm{H}_{2} \mathrm{CO}_{3}\right)$ :

$$
\mathrm{CO}_{2}+\mathrm{H}_{2} \mathrm{O} \rightarrow \mathrm{H}_{2} \mathrm{CO}_{3}
$$

O baixo pH desta nova substância acelera o processo de quebra da camada passivadora do aço e, quando entra em reação com o hidróxido de cálcio, $\mathrm{Ca}(\mathrm{OH})_{2}$, resulta na produção, também, do carbonato de cálcio $\left(\mathrm{CaCO}_{3}\right)$, causando o mesmo processo de carbonatação:

$$
\mathrm{H}_{2} \mathrm{CO}_{3}+\mathrm{Ca}(\mathrm{OH})_{2} \rightarrow \mathrm{CaCO}_{3}
$$

O diagnóstico para este processo é feito através de um teste que utiliza a fenolftaleína, líquido incolor, que acusa a alcalinidade da estrutura (ANDRADE, 1992). Após a sua aplicação na superfície do concreto, a coloração avermelhada se apresenta nos locais onde o pH aproxima-se de 12,5. A sua permanência incolor confirma a redução do $\mathrm{pH}$ que acarreta a manifestação da carbonatação. Este tipo de patologia é bastante comum em bases de pilares no subsolo por conta da umidade e pela urina humana que apresenta cloreto de amônio (GENTIL, 2007), e em locais onde há o tráfego de veículos que emitem gás carbônico.

\subsection{2 Íons cloreto}

Em locais litorâneos é bastante comum a ocorrência da corrosão em estruturas de concreto armado devido ao alto teor salino provindo da névoa salina (ANDRADE, 1992). Os íons cloreto presentes no ambiente, ao entrar em contato com a água nas superfícies do concreto, formam moléculas de ácido clorídrico $(\mathrm{HCl})$ que, por ter um pH baixo - substância ácida, reduzem o pH do concreto. Dessa forma a camada passivadora do aço é quebrada e a corrosão se manifesta na armadura. Segundo Alves (1993), a corrosão no aço é acelerada quando há presença de íons cloreto, que reagem com o ferro presente nas armaduras resultando em cloretos férricos:

$$
2 \mathrm{Cl}+\mathrm{Fe} \rightarrow \mathrm{FeCl}_{2}
$$


Esta molécula de cloreto férrico entra em reação com a água, presente nas estruturas, produzindo hidróxido de ferro, precipitando novamente o cloreto, tornando esta reação um ciclo.

$$
\mathrm{FeCl}_{2}+2 \mathrm{H}_{2} \mathrm{O} \rightarrow \mathrm{Fe}(\mathrm{OH})_{2}+2 \mathrm{Cl}
$$

Diferentemente do processo de carbonatação, a presença dos íons cloreto na corrosão é uma manifestação patológica pontual. Quando o cloreto entra na reação, ele mesmo é precipitado (GENTIL, 2007). Por este motivo, este ataque que facilita a corrosão é chamado de localizada ou pontual. Dentre todas as formas de corrosão, esta é a mais agressiva e mais comum nas edificações (ANDRADE, 1992).

\subsubsection{Corrosão}

Para Gentil (2011), uma manifestação patológica muito indesejada em qualquer tipo de estrutura é a corrosão, que se caracteriza pela deterioração - geralmente de uma peça metálica - de uma peça estrutural e é causada por agentes externos que agridem a sua resistência como, também, acarreta um gasto muito alto com a sua recuperação.

Exitem três tipos de ocorrência de corrosão: eletroquímica (quando há presença de água nos metais), química (quando há presença de algum agente químico responsável pela deterioração) e eletrolítica (quando ocorre a aplicação externa de uma corrente elétrica). A corrosão, em construções civis, é muito comum nas peças de aço - sendo esta do tipo eletroquímica - mas também é recorrente em peças de concreto se não forem tomadas as devidas precauções previstas por norma.

Em regiões onde ocorre um ciclo de molhagem e secagem alternadas do concreto, a corrosão tem um aumento na sua velocidade de deterioração, que agregado à variação de temperatura como, também, na redução do $\mathrm{pH}$ da estrutura, destroem a camada passivadora do aço. Por este motivo, regiões litorâneas sofrem com mais frequência a este tipo de ataque (ALVES, 1993).

A presença da água, o tipo do solo presente, a incidência de gases, produtos químicos, e até mesmo a atmosfera, são os meios corrosivos mais frequentes. Ataques realizados pelo alto teor salino só são possíveis por conta da atmosfera que realiza o transporte destes íons para a região costeira através de ventos, chuvas e ondas (GENTIL, 1982). A maresia tem um poder corrosivo muito grande que, quando ataca a armadura, pode comprometer a estrutura (HELENE, 1986).

Os poros presentes no concreto permitem a penetração de substâncias líquidas, sólidas e gasosas, tornando-o permeável - facilitando ainda mais a corrosão (ANDRADE, 1992).

A principal preocupação em proteger a armadura é evitar a corrosão para que a resistência do aço não seja comprometida. Uma das formas de proteção física é no aumento de uma camada protetora que reduz o avanço de agressores até a armadura. Esta camada, chamada de cobrimento, é dimensionada devido à classe de agressividade do ambiente, podendo variar entre 20 a 55 milímetros (ABNT, 2014).

Segundo a norma, NBR 6118/14, que estabelece os parâmetros para a confecção do concreto armado, as estruturas devem conter uma camada de concreto que dificulte a penetração de substâncias provindas do meio externo, servindo como uma barreira física. Fatores como a composição do cimento, a capacidade de penetrabilidade de água no concreto, a concentração de gás carbônico emitido no ar, respingos de maré que atingem as estruturas, entre outros, podem estar relacionados com a forma de corrosão que se manifesta (HELENE, 1992). As duas principais formas que favorecem a manifestação de corrosão são a carbonatação e o ataque por íons cloretos, mencionados anteriormente.

A boa relação entre o concreto e o aço é devido a um coeficiente de dilatação de ambos muito próximos um do outro, porém, a iteração química entre os mesmos possibilita uma alcalinidade que garante a existência da camada passivadora, esta que protege a armadura presente da corrosão (ANDRADE, 1992).

\section{METODOLOGIA}

Este tópico tem como finalidade descrever a metodologia de estudo que foi aplicada no trabalho, como também no detalhamento do levantamento de dados característicos do local escolhido para estudo. Esta pesquisa se classifica como qualitativa visto que as manifestações patológicas necessitaram de uma análise prévia para que ocorresse uma avaliação de cada caso encontrado. Foram coletados dados no campo que serão avaliados e solucionados da forma mais correta para cada situação, sendo desenvolvidos através de uma revisão bibliográfica e estudo de caso. 


\subsection{Objeto de estudo}

O Balneário Atalaia, localizado na cidade de Luís Correira - Piauí, é um local ativo e recebe funcionários de diversos órgãos do Estado do Piauí para hospedagem, principalmente no período de férias. Sua construção foi iniciada no ano de 1989 quando o governador do Estado ainda era Alberto Silva. O complexo é composto por 5 (cinco) edifícios para hospedagem, uma recepção, um restaurante, uma piscina e um auditório (Figura 1) - este que foi objeto do estudo deste trabalho.

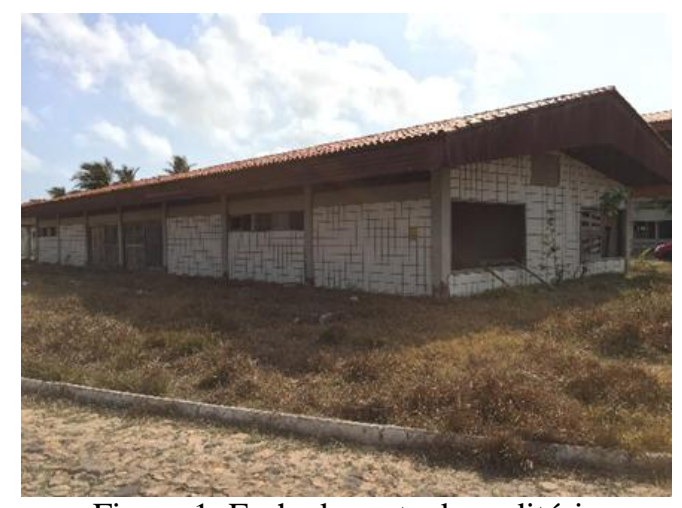

Figura 1: Fachada oeste do auditório

Segundo informações de funcionários do balneário, a última manutenção realizada nas áreas comuns do complexo, incluindo a do auditório, foi realizada há mais de dez anos. As estruturas próximas ao auditório estão sofrendo, também, com as manifestações patológicas decorrentes das falhas construtivas, e não obtiveram nenhum tipo de vistoria para a avaliação de reforço, reparo ou manutenção previsto por norma. A Figura 2, abaixo, mostra o esquema das estruturas de concreto armado do auditório.

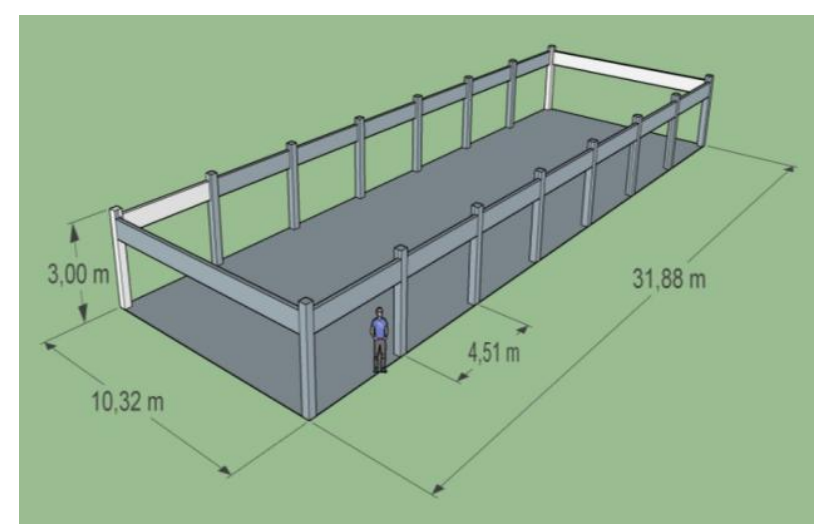

Figura 2: Esquema das estruturas de concreto armado do auditório

O local estudado é composto por 16 pilares com seção transversal de $31 \mathrm{~cm} \times 31 \mathrm{~cm}$ (Figura 3), de aproximadamente 3 metros, e 16 vãos de vigas com seção transversal de aproximadamente $14 \mathrm{~cm}$ x $60 \mathrm{~cm}$ (Figura 4). Utilizou-se de números e letras para identificar cada um deles no estudo de campo e fez-se as devidas anotações da descrição do local onde cada um se encontrava para análise de dados com o intuito de juntar todas as informações necessárias para o estudo. 


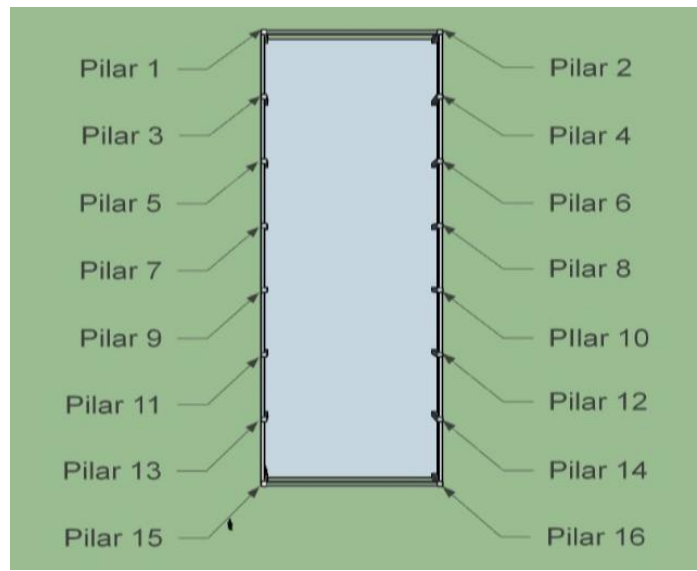

Figura 3: Identificação dos pilares $(31 \mathrm{~cm} \times 31 \mathrm{~cm})$ do auditório

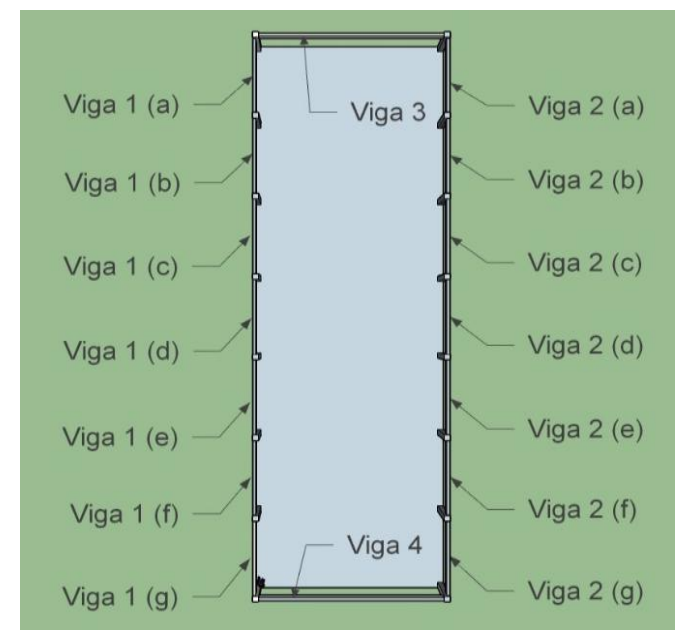

Figura 4: Identificação dos vãos das vigas $(14 \mathrm{~cm} \times 60 \mathrm{~cm})$ do auditório

Por conta da homogeneidade dos resultados encontrados quantos às manifestações patológicas previstas nas superfícies, foram escolhidas apenas algumas das estruturas analisadas para o preenchimento do checklist (item 3.2) com a intenção de simplificar os resultados encontrados. Entretanto, esta escolha não foi elaborada aleatoriamente. Decidiu-se que os pontos estratégicos seriam aqueles que apresentaram resultados diferentes vistoriados em campo, e deveriam levar em consideração a posição geográfica da estrutura referente aos ataques externos tanto do vento como do sol. Desse modo, escolheu-se os pontos extremos do auditório onde as incidências do vento e dos raios solares são diferentes e, portanto, influenciaram os resultados dos pilares. Portanto, escolheu-se os pilares: 1, 2, 15 e 16. Já os vãos das vigas foram escolhidos conforme a diferença de resultados colhidos e analisados em campo. Com isso, os vãos escolhidos foram: 1(a), 2(a), 2(e) e 2(f), conforme Figura 5. Devido o limite de páginas do artigo, serão mostrados o check-list do Pilar 1 e da Viga 1 (a).

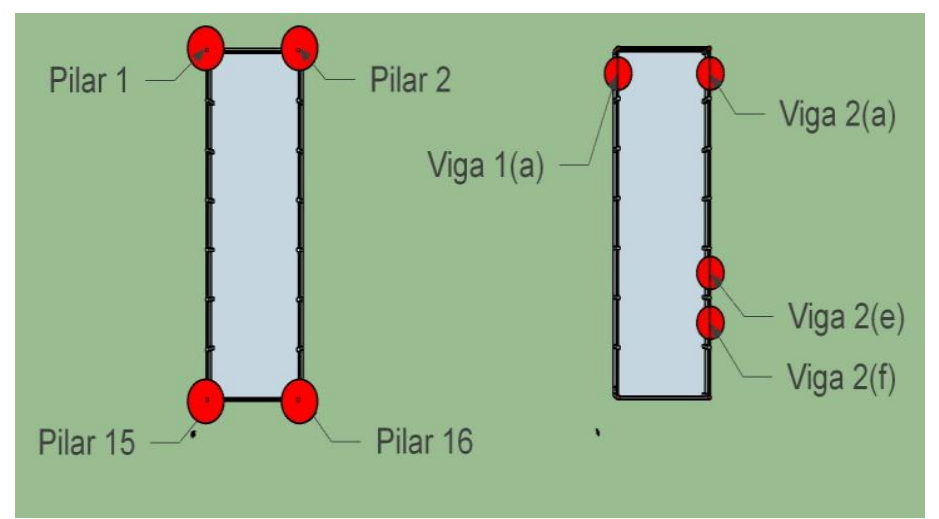

Figura 5: Estruturas selecionados para preenchimento do checklist 
Classifificou-se o local onde cada manifestação patológica se encontra devido a sua agressividade, disposto no Quadro 1.

\begin{tabular}{|c|c|c|}
\hline \multicolumn{2}{|c|}{ Quadro 1: Nível de agressividade das manifestações patológicas } \\
\hline $\begin{array}{c}\text { NIVEL } \\
\text { SATISFATÓRI0 }\end{array}$ & Sem manifestações patológicas \\
\hline $\begin{array}{c}\text { NÍVEL } \\
\text { TOLERÁVEL }\end{array}$ & Poucas manifestações patológicas \\
\hline NÍVEL ALERTA & $\begin{array}{r}\text { Mancha de corrosão da armadura, desagregação por ataque químico, destacamento } \\
\text { localizado no elemento, exposição da armadura no elemento. }\end{array}$ \\
\hline NÍVEL CRÍTICO & Fissuração, destacamento generalizado no elemento, exposição da armadura \\
& generalizada, redução na secção da armadura. & \\
\hline
\end{tabular}

\subsection{Check-list}

Foi elaborado um check-list (Figura 6) para identificação dos elementos estruturais.

\section{IDENTIFICAÇÃO DA ESTRUTURA}

Neste campo serão dispostas as fotografias retiradas em campo para uma melhor visualização das patologias nos locais específicos.

\begin{tabular}{|c|c|c|}
\hline \multirow[b]{2}{*}{$\begin{array}{l}\text { Descrição do local } \\
\text { e da estrutura }\end{array}$} & \multirow{2}{*}{$\begin{array}{l}\text { Neste campo será descrito o local onde a } \\
\text { estrutura se encontra e algumas } \\
\text { informações pertinentes quanto ao seu } \\
\text { estado }\end{array}$} & Localização na planta \\
\hline & & \multirow{5}{*}{$\begin{array}{l}\text { Em miniatura, será } \\
\text { disposto neste campo o } \\
\text { esboço da planta do } \\
\text { auditório indicando em } \\
\text { qual local a estrutura } \\
\text { analisada está disposta. }\end{array}$} \\
\hline Fenolftaleína & $\begin{array}{l}\text { Neste campo será descrito o resultado após } \\
\text { aplicação do indicador de pH na estrutura de } \\
\text { concreto. }\end{array}$ & \\
\hline Nitrato de prata & $\begin{array}{c}\text { Neste campo será descrito o resultado após } \\
\text { a aplicação de nitrato de prata na estrutura } \\
\text { de concreto. }\end{array}$ & \\
\hline Cobrimento & $\begin{array}{c}\text { Neste campo será descrito o cobrimento da } \\
\text { estrutura analisado em campo. }\end{array}$ & \\
\hline \multicolumn{2}{|c|}{$\begin{array}{l}\text { Neste campo será descrito o nível de agressividade da estrutura } \\
\text { analisada em campo pelos autores. }\end{array}$} & \\
\hline
\end{tabular}

\section{RESULTADOS}

Figura 6: Check-list para identificação dos elementos estruturais e das patologias

O teste com a fenolftaleína, indicador ácido-base, quando realizado, mostrou a redução do pH em todas as estru uras, o que garante a quebra da camada passivadora que protege o aço. $\mathrm{O}$ teste com nitrato de prata $\mathrm{AgNO}$, quando aplicado nas estruturas, mostrou a precipitação dos cloretos presentes, confirmando o alto teor de cloretos nas superfícies. As estrutufas, como um todo, do local de estudo estavam em um nível crítico e com indícios de uma má execução de reparo estrutual.

\section{Descrição do local \\ e da estrutura \\ Fenolftaleína \\ Neste campo será descrito o local onde a estrutura se encontra e algumas informações pertinentes quanto ao seu estado

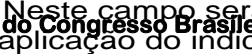 concreto.}

Neste campo será descrito o resultado após a aplicação de nitrato de prata na estrutura
Localização na planta

Em miniatura, será disposto neste campo o esboço da planta do cBaatrzoro indicando em qual local a estrutura analisada está disposta. 


\subsection{Check-List Preenchidos}

Os resultados presentes neste trabalho foram coletados no dia 14 de setembro de 2019 pelos autores deste trabalho. Seguindo o planejamento elaborado previamente, registrou-se imagens com uma câmera fotográfica dos pilares e das vigas, aplicou-se a fenolftaleína e o nitrato de prata nas regiões onde as armaduras estavam expostas e mensuramos os cobrimentos possíveis. Com isso, preencheu-se o check-list dos pilares e vigas que obtiveram os resultados mais divergentes quanto aos dados coletados e foram dispostos neste item com as características encontradas. Através dos resultados obtidos, e das análises feitas em campo, percebeu-se a agressividade da maresia agregada ao vento nas estruturas de concreto. $\mathrm{O}$ vento segue fluxo vindo da região nordeste indo para a sudeste. Portanto, toda a fachada leste, que recebe o vento mais diretamente, obteve uma maior manifestação de patologias.

As superfícies nesta fachada estavam mais corroídas, com perda de seção da armadura, presença de fissuras mais evidentes e manchas de umidade. Já a fachada oeste estava menos degradada e com menos evidências de fissuras. Todos os pilares estavam com armaduras expostas e cobrimentos destacados na altura das suas bases. Porém, os pilares da fachada leste obtinham as exposições de armaduras e destacamentos do cobrimento na sua superfície inteira. As vigas da fachada oeste estavam em situações toleráveis, sem exposição de armadura, com a presença de algumas fissuras localizadas na altura do cobrimento inferior da viga. As vigas da fachada leste estavam em situação crítica, com manchas de umidade, manchas de corrosão e exposição de armadura. A expansão da armadura, causada pelo produto da corrosão, ocasiona em um esforço maior que a resistência do concreto, por isso o aparecimento dessas fissuras foi evidenciado.

A seguir, estão apresentados os check-list do Pilar 1 (Figura 7) e da Viga 1 (a) (Figura 8).

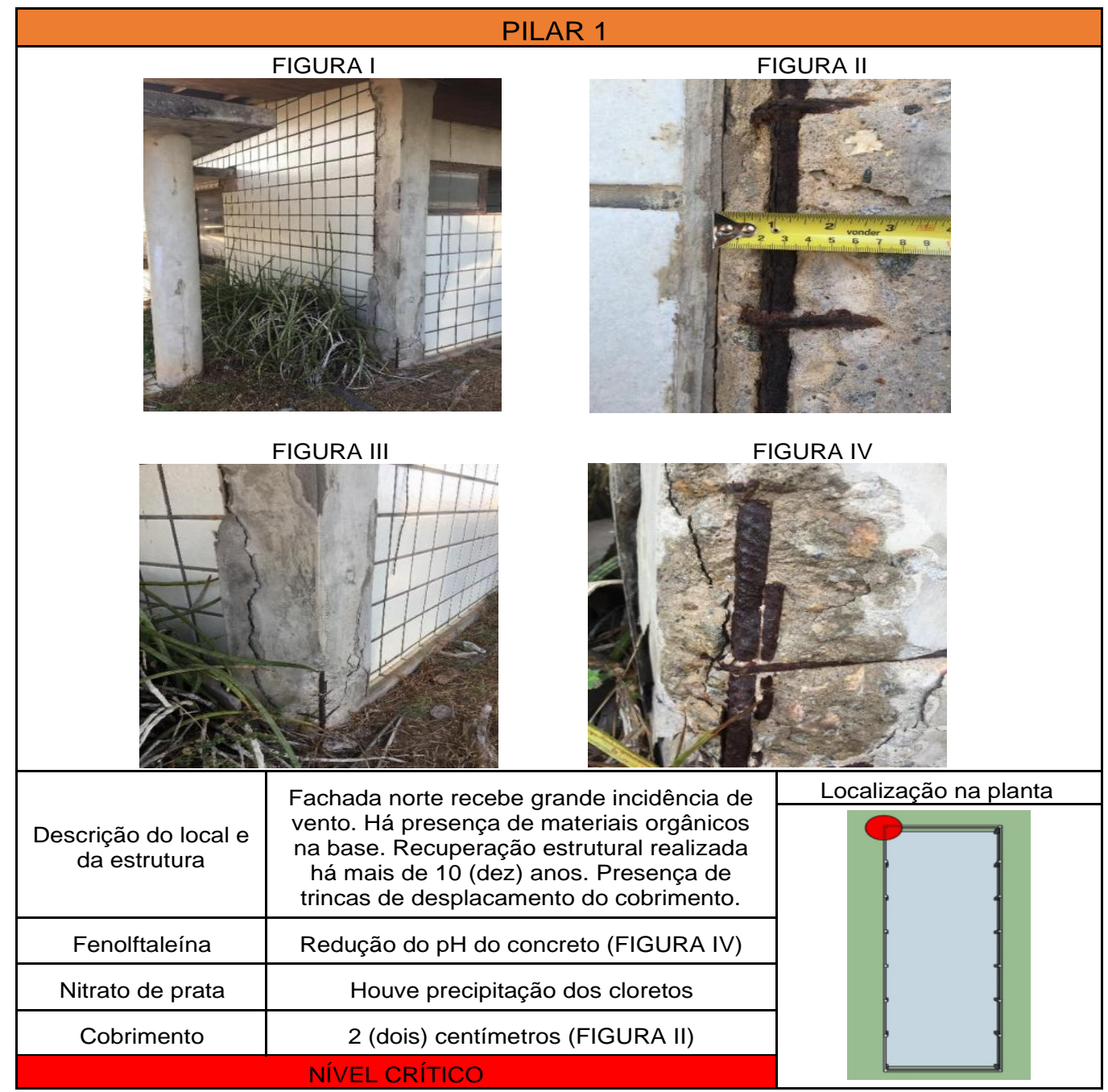

Figura 7: Check-list de identificação do Pilar 1 


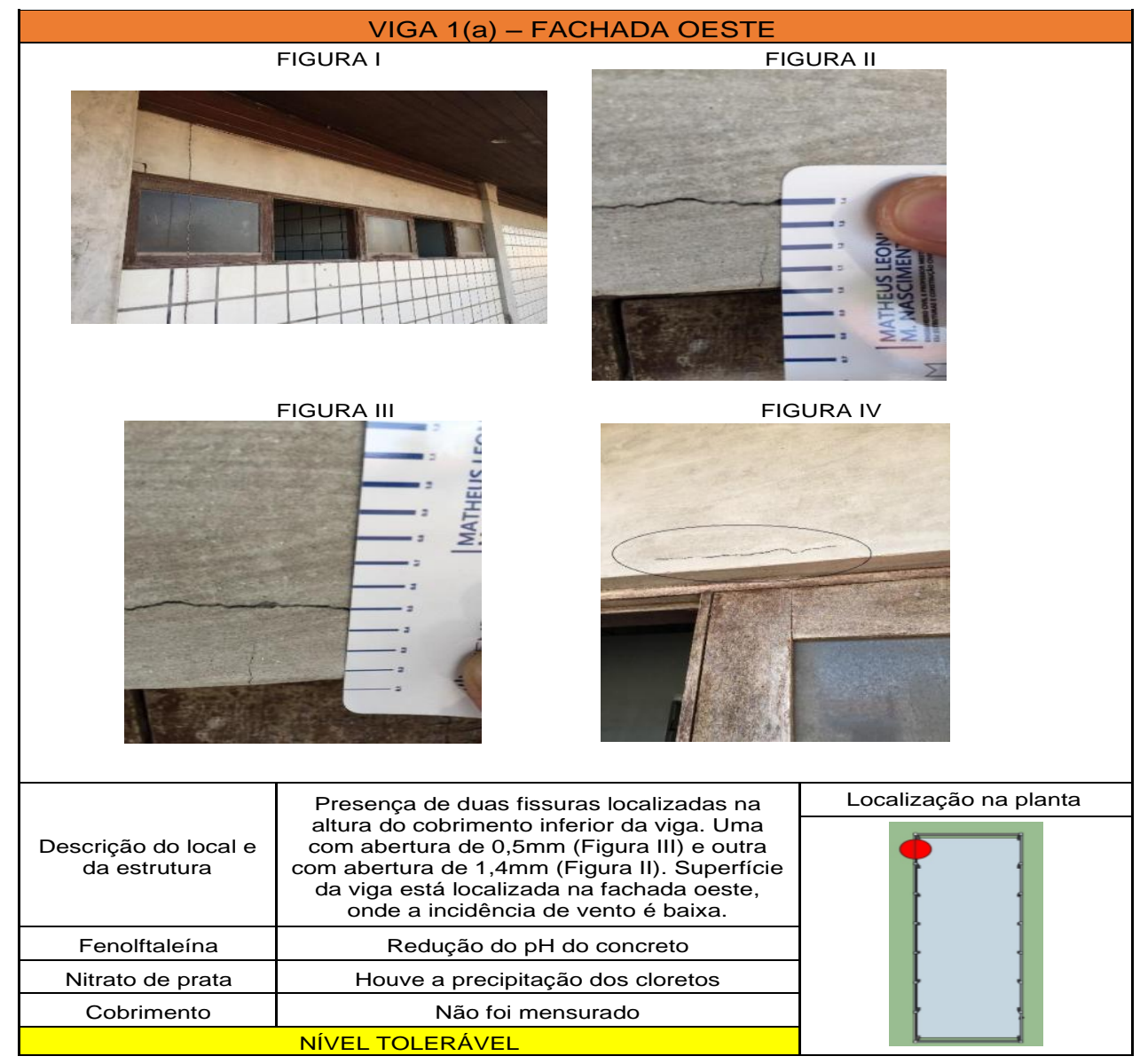

Figura 8: Check-list de identificação da viga 1(a)

\subsection{Mapeamento das manifestações patológicas}

As manifestações patológicas encontradas em campo de todos os pilares foram dispostas no Quadro 2, abaixo.

Quadro 2 - Mapeamento das manifestações patológica nos pilares

\begin{tabular}{|c|c|c|c|c|c|}
\hline Pilares & Cobrimento & $\begin{array}{c}\text { Precipitado com } \\
\mathrm{AgNO}_{3}\end{array}$ & $\begin{array}{c}\text { Teste com } \\
\text { fenolftaleína }\end{array}$ & $\begin{array}{c}\text { Armaduras } \\
\text { expostas }\end{array}$ & $\begin{array}{c}\text { Nível de } \\
\text { agressividade }\end{array}$ \\
\hline Pilar 1 & 2,0 & Sim & Incolor & Sim & Crítico \\
\hline Pilar 2 & 2,0 & Sim & Incolor & Sim & Crítico \\
\hline Pilar 3 & 2,0 & Sim & Incolor & Sim & Alerta \\
\hline Pilar 4 & 1,5 & Sim & Incolor & Sim & Crítico \\
\hline Pilar 5 & 2,0 & Sim & Incolor & Sim & Alerta \\
\hline Pilar 6 & 2,0 & Sim & Incolor & Sim & Crítico \\
\hline Pilar 7 & 2,0 & Sim & Incolor & Sim & Alerta \\
\hline Pilar 8 & 2,0 & Sim & Incolor & Sim & Crítico \\
\hline Pilar 9 & 2,0 & Sim & Incolor & Sim & Alerta \\
\hline Pilar 10 & 2,0 & Sim & Incolor & Sim & Crítico \\
\hline Pilar 11 & 2,0 & Sim & Incolor & Sim & Alerta \\
\hline Pilar 12 & 2,0 & Sim & Incolor & Sim & Crítico \\
\hline Pilar 13 & 1,5 & Sim & Incolor & Sim & Alerta \\
\hline Pilar 14 & 2,0 & Sim & Incolor & Sim & Crítico \\
\hline Pilar 15 & 2,0 & Sim & Incolor & Sim & Alerta \\
\hline Pilar 16 & 2,0 & Sim & Incolor & Sim & Crítico \\
\hline
\end{tabular}


As manifestações patológicas encontradas em campo de todos os vãos das vigas foram dispostas no Quadro 3.

No mapeamento das vigas analisadas em campo, o cobrimento não foi mensurado pela falta de equipamentos, porém, em alguns pontos pôde-se notar um cobrimento insuficiente para a proteção das armaduras.

Quadro 3: Mapeamento das manifestações patológicas nos vãos das vigas

\begin{tabular}{|c|c|c|c|c|c|}
\hline Vigas & $\begin{array}{c}\text { Precipitado com } \\
\text { AgNO3 }\end{array}$ & $\begin{array}{c}\text { Teste com } \\
\text { fenolftaleína }\end{array}$ & $\begin{array}{l}\text { Armaduras } \\
\text { expostas }\end{array}$ & $\begin{array}{l}\text { Trincas e } \\
\text { Fissuras }\end{array}$ & $\begin{array}{c}\text { Nível de } \\
\text { agressividade }\end{array}$ \\
\hline 1(a) & Sim & Incolor & Não & Sim & Tolerável \\
\hline 1(b) & Sim & Incolor & Não & Não & Tolerável \\
\hline $1(\mathrm{c})$ & Sim & Incolor & Não & Não & Tolerável \\
\hline 1(d) & Sim & Incolor & Não & Não & Tolerável \\
\hline $1(\mathrm{e})$ & Sim & Incolor & Não & Não & Tolerável \\
\hline $1(f)$ & Sim & Incolor & Não & Não & Tolerável \\
\hline $1(\mathrm{~g})$ & Sim & Incolor & Não & Não & Tolerável \\
\hline 2(a) & Sim & Incolor & Sim & Sim & Crítico \\
\hline 2(b) & Sim & Incolor & Sim & Sim & Alerta \\
\hline 2(c) & Sim & Incolor & Sim & Sim & Alerta \\
\hline 2(d) & Sim & Incolor & Sim & Sim & Alerta \\
\hline $2(\mathrm{e})$ & Sim & Incolor & Sim & Sim & Alerta \\
\hline $2(f)$ & Sim & Incolor & Sim & Sim & Crítico \\
\hline $2(\mathrm{~g})$ & Sim & Incolor & Sim & Sim & Alerta \\
\hline 3 & - & - & - & - & - \\
\hline 4 & - & - & - & - & - \\
\hline
\end{tabular}

\subsection{Mensuração dos cloretos nos pilares}

Para a quantificação de cloretos nos corpos de prova retirados dos pilares, utilizou-se o método de Mohr. Para esta etapa, analisamos os pontos onde o cobrimento estava destacado, o que possibilitou a extração de corpos de provas, levamos ao laboratório de química da Universidade Federal do Piauí, e obtivemos os seguintes resultados (Quadro 4) utilizando nitrato de prata e cromato de potássio, assim como água pura disponibilizada em laboratório.

Quadro 4: Quantidade necessária de nitrato de prata para titulação
\begin{tabular}{|c|c|c|}
\hline Quantidade de AgNO3, em mL, necessária para a titulação \\
\hline PILAR & Amostra 1 (mL) & Amostra 2 (mL) \\
\hline P1 & 38,7 & 38,5 \\
\hline P2 & 45,5 & 47,4 \\
\hline P7 & 18,6 & 16,6 \\
\hline P15 (superfície interna) & 39,8 & - \\
\hline P15 (superfície externa) & 3,3 & 3,3 \\
\hline P16 & 43,7 & 43,4 \\
\hline
\end{tabular}

A amostra 2 do pilar 15, relativo à parte interna da estrutura, evaporou durante o tempo de espera da absorção dos íons cloreto. Portanto, para este, utilizou-se apenas o valor relativo à amostra 1. 
Quadro 5: Teor de íons cloretos relacionados à massa do concreto

\begin{tabular}{|c|c|c|}
\hline PILAR & Quantidade de cloreto $(\mathbf{m g})$ em 20g do concreto & \% de cloreto na estrutura \\
\hline P1 & 381,4637 & 1,907 \\
\hline P2 & 467,2191 & 2,336 \\
\hline P7 & 183,391 & 0,917 \\
\hline P15 (superfície interna) & 329,3063 & 1,647 \\
\hline P15 (superfície externa) & 34,499 & 0,172 \\
\hline P16 & 430,7484 & 2,154 \\
\hline
\end{tabular}

Os valores encontrados de massa de cloreto na estrutura são limitados a um valor máximo de 0,4\% dos íons relacionados à massa do cimento. Por conta da ausência de laboratórios específicos para definir a massa de cimento nos corpos de prova, não foi possível encontrar esses resultados de uma forma mais precisa. Porém, com os valores encontrados, que se relacionavam à massa do concreto, pode-se afirmar que o máximo de cloretos foi ultrapassado de uma forma genérica.

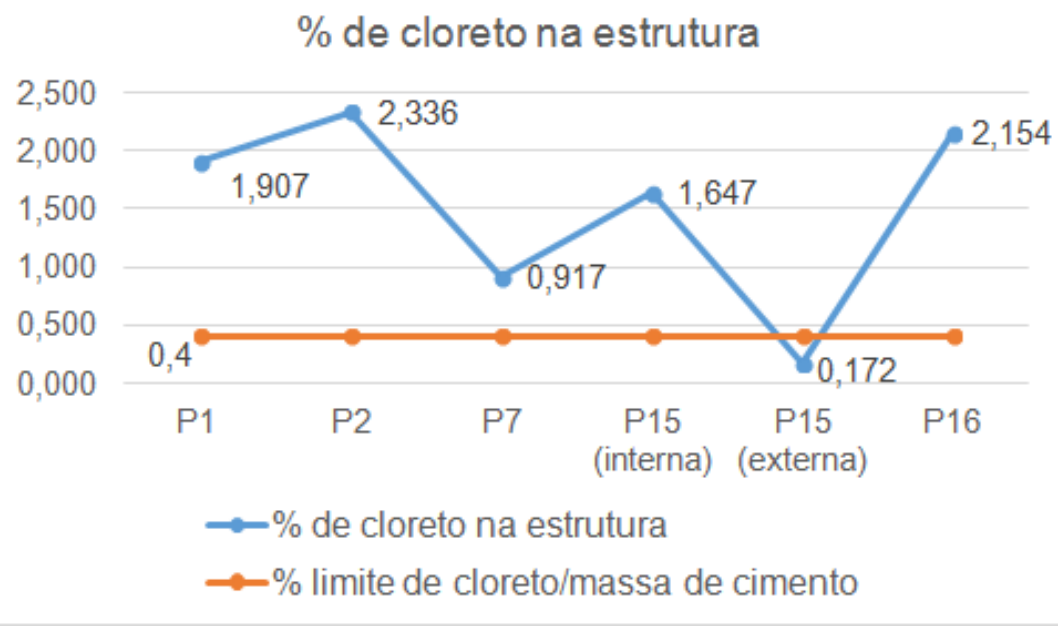

Figura 8: Comparativodos limites de cloretos permitidos (\% Cl/massa de cimento)

Os pilares 2 e 16 foram os que apresentaram os valores mais expressivos, ultrapassando a marca de $2 \%$ de massa de cloreto na estrutura, por conta da posição geográfica das peças. Ambos se localizam na fachada leste que recebe uma maior incidência de ventos, este responsável pelo transporte da maresia, e por isso foram os que obtiveram tais resultados.

\section{CONCLUSÃO}

Conforme se esperava, o ataque da maresia na estrutura, agregado às falhas construtivas, possibilitaram um ataque à corrosão muito grande em relação às outras manifestações patológicas. Em algumas estruturas, a incidência do vento era maior, o que influenciou no diagnóstico de alguns casos quanto à degradação presente. A recomendação feita pela norma 6118/2014 prevê o ataque provindo do ambiente e aconselha a execução de um cobrimento específico para proteção da armadura contra esse ataque. Pela classe de agressividade do ambiente, o cobrimento do concreto confeccionado na edificação deveria possuir $40 \mathrm{~mm}$ de espessura. Como foi visto em campo essa dimensão não foi respeitada, já que todas as estruturas analisadas obtinham um cobrimento de, no máximo, $20 \mathrm{~mm}$ (metade do recomendado).

A corrosão provoca no aço um esforço de tensão que possibilita a sua expansão que ocasiona o destacamento do concreto e acelera ainda mais a corrosão em outros pontos da estrutura. Por isso, em campo, foi possível identificar as estruturas deterioradas com o cobrimento destacado, já que a armadura longitudinal e os estribos localizam-se em contato com o concreto destinado ao cobrimento. Em alguns casos, a tensão foi tão grande que ocorreu o rompimento da armadura do estribo. A abertura de poros através de fissuras e trincas permite a entrada do gás carbônico provindo do 
ambiente e de automóveis, que trafegam pelas proximidades, e quando reagem com o concreto realizam o processo de carbonatação. Por conta disso, as análises feitas em campo, com o indicador de pH (fenolftaleína), acusaram a redução da alcalinidade da estrutura. Dessa forma, a corrosão se manifesta de forma generalizada, em toda a barra de aço.

O local está inativo, mas vale ressaltar que ele está localizado em um balneário que abriga hóspedes e, por estar em uma área comum, e de fácil acesso, pode-se tornar um problema quanto à sua inatividade gerando problemas por conta do seu uso. Deve-se atentar quanto aos cuidados para garantir a segurança, o bem-estar e o desempenho da estrutura.

\section{REFERÊNCIAS}

ALVES, Jose Dafico. Manual de Tecnologia do Concreto. UFG, Goiânia, 1993.

ANDRADE, C. Manual para Diagnóstico de Obras Deterioradas por Corrosão de Armaduras. Editora Pini, p. 104, São Paulo, Brasil (1992).

ASSOCIAÇÃO BRASILEIRA DE NORMAS TÉCNICAS (ABNT). NBR 6118: Projeto de estruturas de concreto Procedimento. Rio de Janeiro, 2014.

BRANDÃO, Ana Maria da Silva. Qualidade e durabilidade das estruturas de concreto armado - aspectos relativos ao projeto. São Carlos, 1998.

GENTIL, Vicente. Corrosão. 2. ed. Rio de Janeiro: LTC, 1982.

GENTIL, Vicente. Corrosão. 5. ed. Rio de Janeiro: LTC, 2007.

GENTIL, Vicente. Corrosão. 6. ed. Rio de Janeiro: LTC, 2011.

HELENE, Paulo Roberto do Lago. Corrosão em armaduras para concreto armado. PINI. São Paulo, 1986.

HELENE, Paulo Roberto do Lago. Manual para reparo, reforço e proteção de estruturas de concreto. 2. ed. São Paulo: Pini, 1992.

MENDES, Natália Luiza de Oliveira. Patologia em Pontes de Concreto Armado: Causas e Prevenções. Campo Grande, 2018.

MILITITSKY, Jarbas; CONSOLI, Nilo Cesar; SCHNAID, Fernando. Patologia das fundações. 2. ed. rev. e ampl. -São Paulo : Oficina de Textos, 2008.

PORTELLA, Caio Sander Andrade. Avaliação da durabilidade de concretos produzidos segundo a ABNT NBR 6118:2007 e expostos aos cloretos disseminados em névoa salina na Praia do Futuro, em Fortaleza/CE. Fortaleza, 2013. 